\title{
An Attempt to Produce Cholinergic Hypofunction in Rat Brain using Choline Mustard Aziridinium Ion: Neurochemical and Histological Parameters
}

\author{
E.H. Colhoun, L.A. Myles and R.J. Rylett
}

\begin{abstract}
Deficiencies in cholinergic nerve function have been clearly documented in patients with Alzheimer's disease. The lack of this neurotransmitter may be responsible for early memory loss in patients with the disease. Choline mustard Az ion has been used in our laboratory to produce cholinergic hypofunction in rat brain. Injections of the compound into the medial septal nucleus and dorsal hippocampus produced tissue lesions. The lesions were dose and time-dependent. Lesions produced in the medial septum resulted in transmitter depression in the hippocampus. These results suggest non-specific tissue damage because 5-HT levels were lower than normal. Other strategies for getting choline mustard Az ion into rat brain are being investigated to circumvent the apparent ability of this compound and other nitrogen mustard analogs of choline to produce non-specific tissue damage when injected directly into brain tissue.
\end{abstract}

\begin{abstract}
RÉSUMÉ: Tentative de production d'une hypofonction cholinergique dans le cerveau de rat au moyen de l'aziridinium de moutarde cholinée: paramètres neurochimiques et histologiques. Des déficits au niveau des fonctions nerveuses cholinergiques ont été clairement démontrés chez les patients atteints de la maladie d'Alzheimer. L'absence de ce neurotransmetteur peut être responsable de la perte de mémoire qui survient précocement chez les patients porteurs de cette maladie. L'AZ de moutarde cholinée a été utilisé dans notre laboratoire pour produire un déficit de la fonction cholinergique dans le cerveau de rat. L'injection de cette substance dans le noyau septal médian et dans la région dorsale de l'hippocampe a produit des lésions tissulaires. Les lésions étaient dépendantes des doses injectées et du temps d'injection. Les lésions produites au niveau du septum médian ont entraîné une dépression des neurotransmetteurs dans l'hippocampe. Ces résultats semblent indiquer que les lésions tissulaires sont non-spécifiques, parce que les niveau de 5-HT étaient inférieurs à la normale. Nous explorons d'autres stratégies pour introduire l'AZ de moutarde cholinée dans le cerveau de rat dans le but de contourner la propriété que cette substance, ainsi que d'autres analogues de la choline sous forme de moutarde azotée, semblent posséder de produire des dommages tissulaires non-spécifiques lorsqu'ils sont injectés directement dans le tissu cérébral.
\end{abstract}

Can. J. Neurol. Sci. 1986; 13:517-520

Senile dementia of the Alzheimer type has no known cause nor are there effective treatments to halt its inexorable progress. At least six theories have been advanced to account for the decline in human central nervous function; these are genetic factors, aberrant protein synthesis, aluminum toxicity, altered blood flow, changed metabolic features and a deficiency in cholinergic function. Although there is substantive evidence that a number of chemical transmitter systems are affected in Alzheimer's disease, the deficits associated with markers of the cholinergic nervous system in the human brain are profound and they have been consistently documented by a number of investigators. ${ }^{1,2}$ The loss of cholinergic markers occurs early in the disease process. ${ }^{3}$ Recent memory loss is a feature of the early stages of the disease.

A number of animal models have been proposed for studies with Alzheimer's disease. These include aluminum-treated experimental animals, aged monkeys or rodents, chemicallesioned rats or monkeys, animals treated with cholinergic

From the Departments of Pharmacology/Toxicology (Drs. Colhoun and Myles) and the Department of Physiology (Dr. Rylett), The University of Western Ontario, London, Ontario

Reprint requests to: Dr. E.H. Colhoun. Department of Pharmacology \& Toxicology. Health Sciences. The University of Western Ontario. London. Ontario, Canada N6A $5 \mathrm{Cl}$ 
antagonists or presynaptic blocking agents and hypoxic/anoxic rats. It is unlikely that a true animal model for the disease will be found but it might be possible to produce a model for one specific feature such as memory loss. Towards this end an attempt has been made to utilize ethylcholine mustard aziridinium ion (ECM Az; also known as AF-64A) to produce cholinergic deficits in rat brain [see review by Fisher and $\mathrm{Hanin}^{4}$ ] but reports of non-specific tissue damage when this agent was injected into rat brain have brought into question the sitedirected specificity of it. ${ }^{5,6}$ Over the past 12 years we have studied the mechanism of action of a number of nitrogen mustard analogs of choline in the cholinergic nervous system of rodents with particular emphasis on choline mustard aziridinium ion (ChM Az) and ECM Az. ${ }^{7.8 .9}$ More recently we have been employing ChM Az as a potential in vivo site-directed cholinotoxin keeping in mind the proven ability of this compound in vitro to inhibit the high affinity transport of choline and choline acetyltransferase (CAT) in isolated nerve endings of rat brain. We report aspects of the neurochemical and histological effects of injections of low doses of ChM Az in several regions of rat brain.

\section{METhODS}

Male Sprague-Dawley rats weighing 280-300 g were used in all experiments. Following induction of anesthesia with Equithesin, $3 \mathrm{ml} / \mathrm{Kg}, \mathrm{ChM} \mathrm{Az}$ or isotonic saline was injected bilaterally into the medial septum or dorsal hippocampus via a 31 gauge cannula with a Harvard perfusion pump at a rate of $1 \mathrm{ul} / 8 \mathrm{~min}$. The cannula was left in place for $8 \mathrm{~min}$ following an injection of $\mathrm{ChM} \mathrm{Az}$ or saline. Stereotaxic coordinates for medial septum (AP $0.2 \mathrm{~mm}$. $0 \mathrm{~mm}$ midline, $6.3 \mathrm{~mm}$ ventral to skull) and dorsal hippocampus (AP $-4.3 \mathrm{~mm},+2.5 \mathrm{~mm}$ midline, $3.8 \mathrm{~mm}$ ventral to skull ) were according to the atlas of Paxinos and Watson. ${ }^{10}$

ChM Az was obtained by alkaline hydrolysis ( $\mathrm{pH} 11.0$ for 10 min with $\mathrm{NaOH}$ ) of acetylcholine mustard synthesized in our laboratory. This agent as the free base $(10 \mathrm{mM})$ was dissolved in physiological saline and left at ambient room temperature (about $23^{\circ} \mathrm{C}$ ) for $50 \mathrm{~min}$ to form the aziridinium ion (Az) species. Drug solutions were prepared daily and dilutions of the stock solution were made with sterile physiological saline buffered to $\mathrm{pH}$ 7.4. Concentrations of the biologically active Az ion species in solution were determined for each stock solution by the iodine-thiosulfate titration method. " All concentrations of ChM $\mathrm{Az}$ are reported as the Az ion. Purity of the synthesized acetylcholine mustard was never less than 97 per cent and contamination by methyl-bis-chloro-ethylamine as determined by mass spectrometry was negligible.

For histological evaluation of ChM Az-treated rat brains the animals were anesthetized and perfused transcardially with cold buffered 10 per cent formalin. Brains were removed, placed in 10 percent formalin and prepared for paraffin embedding. Sections of brain cut at 7 um were stained with hematoxylineosin and counterstained with luxol fast blue.

Synaptosomal transport of choline (CH), 5-hydroxytryptamine (5-HT), noradrenaline (NA), and gamma butyric acid (GABA) was measured according to Kuhar. ${ }^{12}$ Choline acetyltransferase (CAT) was measured radioenzymatically. ${ }^{13}$ Acetylcholine hydrolase (AChE) was determined by a colorimetric technique. ${ }^{14}$ Brain content of 5-HT, dopamine (DA) and NA was measured by high pressure liquid chromatography (HPLC).
Glutamic acid decarboxylase (GAD) activity was quantitated radioenzymatically ${ }^{15}$ using modifications of the $14_{\mathrm{CO} 2}$ trapping method.

\section{RESULTS}

Following injections of ChM Az into the medial septal nucleus of rat brain in the dose range of 0.1 to 3 nmoles in a volume of 1 ul, histological evaluation was carried out, Figure 1 (a-d). No evidence of histological damage was evident in rats injected with isotonic saline, but a dose-dependent tissue damage effect was observed with ChM Az. Doses of ChM Az greater than 1 nmoles caused large necrotic lesions (see Figure $\mathrm{lb}$ as a representative example of the lesion type at 2 nmoles of ChM Az). Doses of ChM Az lower than 1 nmole produced a clearly evident cavitary lesion at the site of injection with glial cell proliferation; the magnitude of this type of lesion depended on the dose of ChM Az. At doses of the mustard agent below I nmole and at high magnification (Figure $1 \mathrm{c}$ ) neuronal perikarya adjacent to the injection site were observed to be degenerating compared with the saline control (Figure Id).

At preselected intervals following the injection of $\mathrm{ChM} \mathrm{Az}$ into the medial septum, cholinergic, monoaminergic and GABAergic markers were determined in the hippocampus (Table 1). It is clearly evident from the data given in Table 1 that there was a significant decrease in the high affinity uptake of choline in synaptosomes prepared from the hippocampus and a reduction in the activity of CAT. These effects were dose-dependent. Of the other neuronal markers examined there was a decrease in the level of 5-HT indicating that axons of passage in the medial septum as well as cholinergic cell bodies were damaged by injections of ChM Az. At the same dose of ChM Az ( 2 nmoles) the loss of cholinergic markers was greater at 21 days than at 10 days after injection indicating time as well as dose dependent factors producing loss of cholinergic function in the hippocampus.

$\mathrm{ChM} \mathrm{Az}$ at doses from 0.05 to 3 nmoles in $1 \mathrm{ul}$ was injected into the dorsal hippocampus. Dose-related tissue lesions were observed, Figure 2(a-c). As shown in Figure 2b, 0.5 nmoles of ChM Az produced a lesion in the hippocampus comparable to that observed for 2 nmoles of the drug injected into the medial septum (Figure 1b). Degeneration of cells in the CA3 region of the brain some distance from the site of injection was clearly discernible (Figure 2c). Doses of the mustard below 1 nmoles produced a cavitary lesion at the site of injection surrounded by an area of proliferating glial cells: administration of 1 to 3 nmoles of ChM Az resulted in gross degenerative lesions in hippocampal tissue. Currently, the neurochemical parameters of a number of neurotransmitters in the hippocampus are being investigated in detail at different doses of ChM Az.

\section{Discussion}

A rodent model with site-directed lesions for the cholinergic nervous system of brain would be invaluable in the study of neurologic and other parameters of Alzheimer's disease. As confusion and loss of recent memory appear to be related to early manifestation of the disease process, a site-specific cholinotoxin would be of great importance for the production of cholinergic hypofunction in one or more regions of the brain and this would lead to studies on memory and learning in the experimental animal species. Of equal importance would be the use of pharmacological intervention techniques to restore the function of the depressed neurotransmitter system. Long-term 

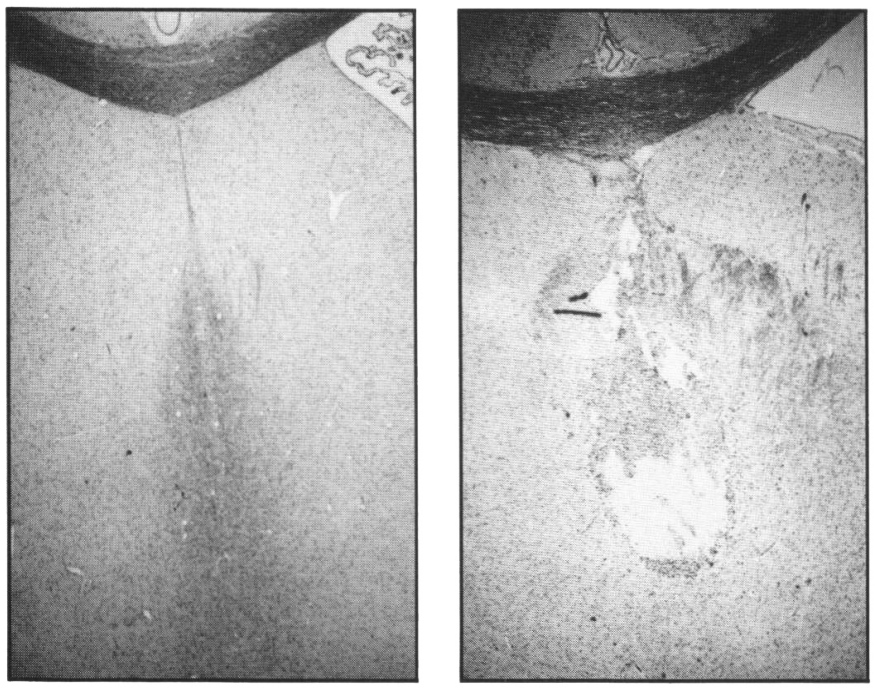

b

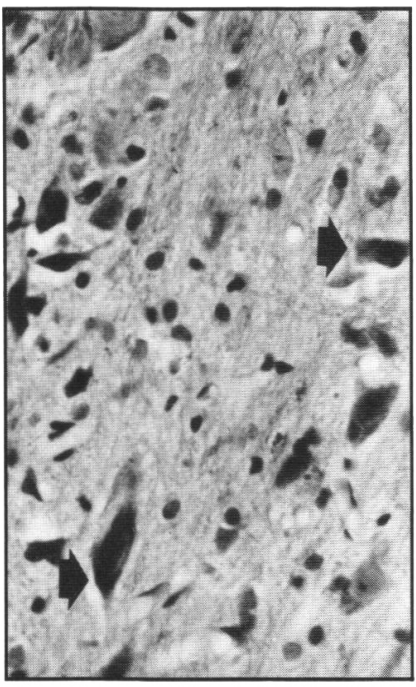

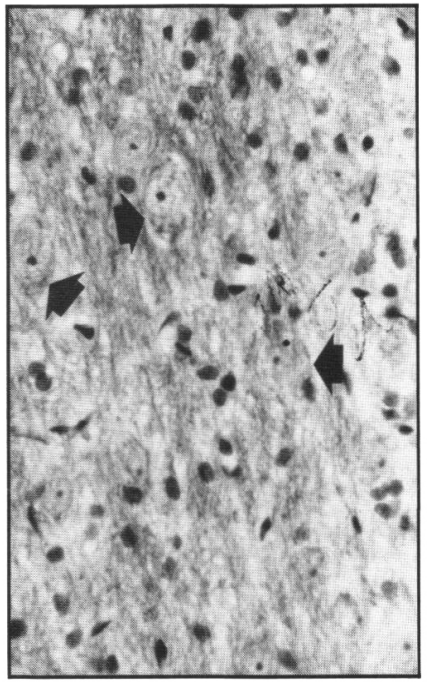

d

Figure 1 - Histological examination of the effects of injections of ChM Az into the medial septal nucleus of rat brain. (a) administration of 1 ul of physiological saline (b) 2 nmoles of ChM Az and the resultant tissue damage (c) higher magnification of neuronal perikarya adjacent to the damage observed in ( $b$ ) arrows show degeneration of the perikarya. (d) higher magnification of perikarya in (a) showing no evidence of degeneration of perikarya.
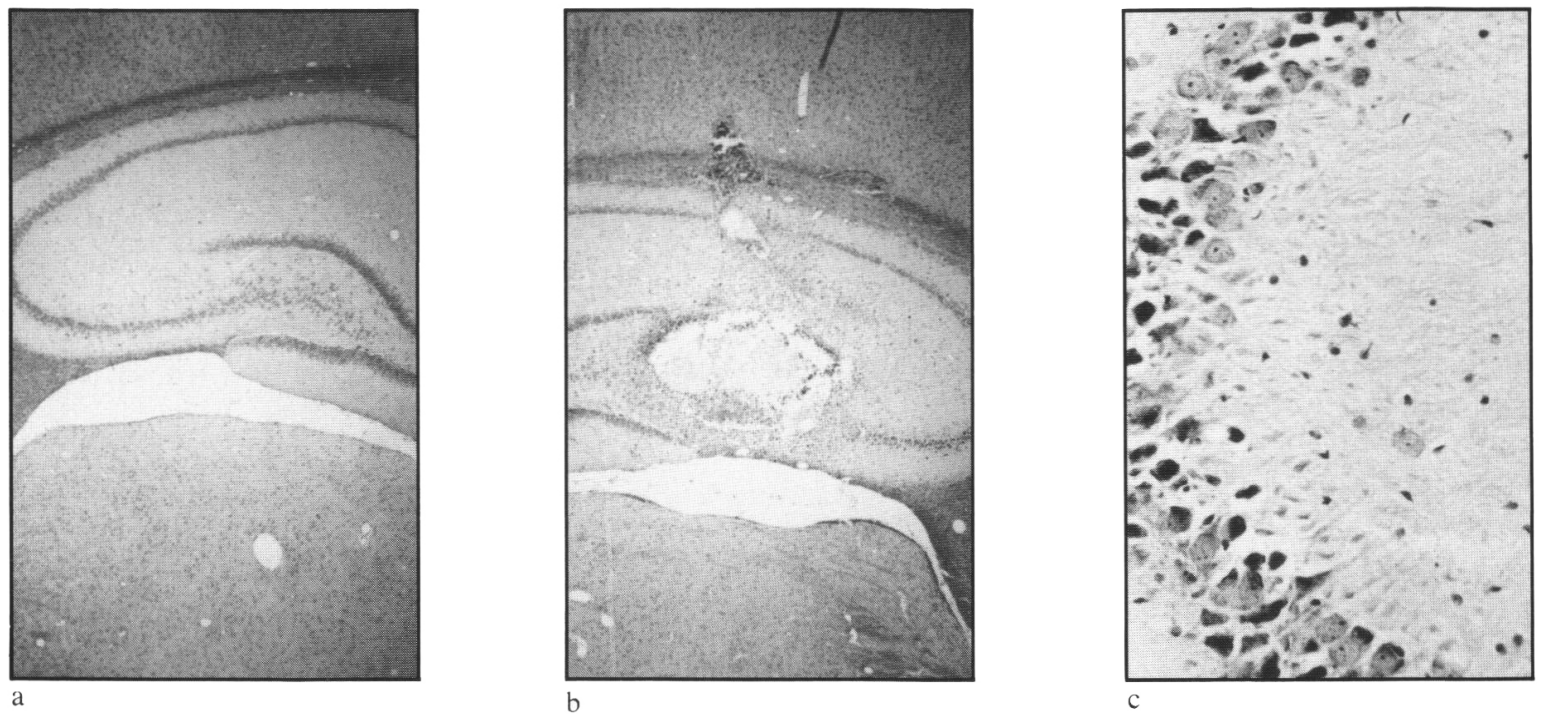

Figure 2 - Histological examination of injections of ChM Az into the dorsal hippocampus of rat brain. (a) Injection of 1 ul of physiological saline. (b) Tissue damage caused by 0.5 nmoles ChM Az. (c) Tissue damage caused by 0.5 nmoles of ChM Az in the CA3 region. Note dark degenerating cells some distance from the site of injection in $(b)$.

Table 1: Effects of ChM Az injected into the medial septum of rat brain on biochemical parameters measured in the hippocampus

\begin{tabular}{|c|c|c|c|c|c|c|c|c|c|c|c|}
\hline \multirow{2}{*}{$\begin{array}{c}\text { Dose } \\
\text { (nmoles) }\end{array}$} & \multirow{2}{*}{$\begin{array}{c}\text { Time } \\
\text { (days) }\end{array}$} & \multicolumn{3}{|c|}{ Content (\% Control) } & \multirow[b]{2}{*}{ 5-HT } & \multirow[b]{2}{*}{ DPA } & \multicolumn{5}{|c|}{ Synaptosomal Transport (\% Control) } \\
\hline & & ChAT & AChE & GAD & & & NA & $\mathbf{C H}$ & GABA & NA & 5-HT \\
\hline 0.3 & 21 & & & & & & & $\begin{array}{r}110.8 \\
(5)\end{array}$ & & & \\
\hline 1.0 & 21 & $\begin{array}{r}102.5 \\
(6)^{*}\end{array}$ & & $\begin{array}{r}93.0 \\
(6)\end{array}$ & & & & $\begin{array}{r}83.1 \\
(5)\end{array}$ & & & \\
\hline 2.0 & 10 & $\begin{array}{l}98.7 \\
(13)\end{array}$ & $\begin{array}{c}46.5^{\S} \\
(8)\end{array}$ & $\begin{array}{r}94.4 \\
(18)\end{array}$ & & & & $\begin{array}{r}87.4 \\
(8)\end{array}$ & $\begin{array}{r}103.2 \\
(8)\end{array}$ & $\begin{array}{r}119.3 \\
(8)\end{array}$ & $\begin{array}{r}71.1 \\
(8)\end{array}$ \\
\hline 3.0 & 21 & $\begin{array}{c}39.9^{8} \\
\text { (4) }\end{array}$ & $\begin{array}{c}52.4^{8} \\
(4)\end{array}$ & & & & & $\begin{array}{c}68.3 \downarrow \\
(6)\end{array}$ & & & \\
\hline
\end{tabular}

* number of animals $\quad$ I $P<0.001$

$\S \mathrm{P}<0.0005 \quad \downarrow \mathrm{P}<0.02$ 
deficits in cholinergic function might show effects on other neurotransmitters or central nervous modulators and the consequences that these might have on central nervous activity.

The purpose of the present study was to extend our in vitro experiments with $\mathrm{ChM} \mathrm{Az}$ to in vivo effects of this cholinotoxin and to determine if the agent could produce specific deficits only in the cholinergic nerve terminals and perhaps cholinergic cell bodies. Initially we injected ChM Az into the medial septal nucleus of rat brain because this area of the brain contains cholinergic cell bodies with well-defined projections to the hippocampus. ${ }^{16}$ The effects of ChM Az injected into the medial septum would thus be tested by measuring neurochemical markers in the hippocampus. If ChM Az had affinity only for cholinergic nerve terminals one would not expect to find cholinergic deficits in the hippocampus. Non-specific tissue damage should produce deficits in a number of neurotransmitter markers in the hippocampus. The second major experimental approach was to determine the effect of $\mathrm{ChM} \mathrm{Az}$ injected into the dorsal hippocampus which contains cholinergic nerve terminals.

The results of our experiments show clearly that ChM Az at the doses used produced tissue damage at the site of injection. The amount of tissue damage was dose-dependent. Thus ChM Az produced lesions in the medial septum which in turn revealed deficits in CAT and high affinity choline transport in the hippocampus. The fact that 5-HT levels were also depressed in the hippocampus indicated that 5-HT axons of passage in the medial septum were being damaged by this nitrogen mustard analog of choline. Similar results were obtained when ChM Az was injected into the dorsal hippocamus. Our histological studies showed tissue destruction at the site of injection and the amount of tissue damage was dose-dependent. Even at low doses of the agent we observed proliferation of glial cells peripheral to the site of injection. At the same dose of chemical, tissue damage was a function of time, i.e damage was greater at 21 days than at 10 days after drug injection.

The ethyl analog of choline mustard, AF 64-A, has been used extensively as a potential site-directed cholinotoxin and as a chemical to produce an animal model of Alzheimer's disease; see $^{4}$ for an extensive review. This agent, however, has been reported to produce non-specific tissue damage. ${ }^{6,17,18}$ In our laboratory we have found (unpublished data) that ECM Az as the free base or the hydrochloride produced non-specific tissue damage and in doses much lower than ChM Az. From these results it is possible that $\mathrm{ChM} \mathrm{Az}$ has greater potential for site-directed neurotoxicity than ECM Az, providing a strategy can be devised for ChM Az that would eliminate its apparent ability to cause tissue damage on injection.

Although our in vitro studies with isolated nerve endings have shown clearly that $\mathrm{ChM} \mathrm{Az}$ has potential as an in vivo cholinotoxin ${ }^{7.8 .9}$ we must conclude that our present studies do not confirm this potential. On the basis of the overall evidence produced by many investigators working with ECM Az we are not yet convinced that this agent can be described as "a sitedirected specific cholinotoxin". This conclusion is based primarily on the current use of the agents being injected directly into nervous tissue. A suitable biological preparation may be found where in a fluid phase ChM Az or ECM Az would not produce the damage found with injections into tissue where the agents can be localized. Intravitreal injections of ECM Az appear to produce selective lesions in the retina of chicks. ${ }^{19}$ Presently, we are employing other strategies to direct $\mathrm{ChM} \mathrm{Az}$ into central nervous tissue. Studies with these nitrogen mustard analogs of choline must include parallel investigations on histology and neurochemistry, particularly where behavioural paradigms are being sought to ensure that the effects observed are not due to non-specific tissue damage.

\section{ACKNOWLEDGEMENTS}

We are grateful for the provision of funds by the Ontario Mental Health Foundation and by The Canadian Geriatric Research Society. The technical assistance of Ms. Heather Towers and Mr. Zbigniew Kujawa is acknowledged.

\section{REFERENCES}

1. Bartus RT, Dean RL, Beer B, et al. The cholinergic hypothesis of geriatric memory dysfunction. Science 1982; 217: 408-417.

2. Bowen DM, Benton JS, Spillane JA, et al. Choline acetyltransferase activity and histopathology of frontal neocortex from biopsies of demented patients. J Neurol Sci 1982; 57: 191-202.

3. Sims NR, Bowen DM, Allen SJ, et al. Presynaptic cholinergic dysfunction in patients with dementia. J Neurochem 1983; 40: 503-509.

4. Fisher A, Hanin I. Potential animal models for senile dementia of Alzheimer's type, with emphasis on AF64A-induced cholinotoxicity. Ann Rev Pharmacol Toxicol 1986; 26: 161-181.

5. Asante JW, Cross AJ, Deakin SF, et al. Evaluation of AF64A as a specific neurotoxin of brain cholinergic neurons. Brit J Pharmacol 1983; 80: 575p.

6. Levy A, Kant GJ, Myerhoff JL, et al. Non-cholinergic neurotoxic effects of AF64A in the substantia nigra. Brain Research 1984; 305: 169-172.

7. Rylett RJ, Colhoun EH. Interactions of choline mustard aziridinium ion with choline acetyltransferase. J Neurochem 1979; 32: 553-558.

8. Rylett RJ, Colhoun EH. Kinetic data on the inhibition of high affinity choline transport into rat forebrain synaptosomes by choline-like compounds and nitrogen mustard analogues. J Neurochem 1980; 34: 713-719.

9. Rylett RJ, Colhoun EH. An evaluation of irreversible inhibition of synaptosomal high-affinity choline transport by choline mustard aziridinium ion. J Neurochem 1984; 43: 787-794.

10. Paxinos $G$, Watson $C$. The rat brain in stereotaxic coordinates. New York, Academic Press, 1982.

11. Golumbic C, Fruton JS, Bergmann M. Chemical reactions of the nitrogen mustard gases. J Org Chem 1946; 11: 518-535.

12. Kuhar MJ, Zarbin MA. Synaptosomal transport: a chloride dependence for choline, GABA, glycine and several other compounds. J Neurochem 1978; 31: 251-256.

13. Fonnum $F$. Isolation of choline esters from aqueous solutions by extraction with sodium tetraphenylboron in organic solvents. Biochem J 1969; 113: 291-298.

14. Ellman GL, Courtney KD, Andres V, et al. A new and rapid colorimetric determination of acetylcholinesterase activity. Biochem Pharmacol 1961; 7: 88-95.

15. Chalmers A, McGeer EG, Wickson H, et al. Distribution of glutamic acid decarboxylase in the brains of various mammalian species. Comp Gen Pharmac 1970; 1: 385-390.

16. Fibiger HC. The organization and some projections of cholinergic neurons of the mammalian forebrain. Brain Res Rev 1982; 4: 327-388.

17. Spencer DG, Horvath E, Luitten $P$, et al. Novel approaches in the study of brain acetylcholine function: neuropharmacology, neuroanatomy, and behaviour. Traber J, Grispen SH, eds. Senile Dementia of the Alzheimer Type. Berlin, Springer-Verlag, 1985; 325-342.

18. Swertka SA, Olson GL. Neuropathology and amphetamine-induced turning resulting from $A F 64 A$ injections into the striatum of the rat. Life Sci 1986; 38: 1105-1110.

19. Morgan IG, Ishimoto I, Boelen M. Selective destruction of the cholinergic amacrine cells of chicken retina with AF64A. Invest Opthalmol vis Sci 1984; 25: suppl. 104. 